\title{
Beobachtungen des Cometen 1884 Wolf.
}

Am Refractor der Kieler Sternwarte.

\begin{tabular}{|c|c|c|c|c|c|c|c|c|c|}
\hline I 884 & M. Z. Kiel & $\Delta c t$ & $\Delta \delta$ & Vergl. & a app. & $\log p .1$ & $\delta$ app. & $\log p \cdot \Delta$ & $*$ \\
\hline Oct. 23 & $9^{h} \quad 2^{m} 20^{s}$ & $+0^{m} 46.85$ & $+2^{\prime} 52.6$ & 8 & $21^{\mathrm{h}} 53^{\mathrm{nl}} 3^{\mathrm{s}} 69$ & 9.075 & $+6^{\circ} 46^{\prime} 5^{6 \prime 8} 8$ & $0.8 \times 5$ & I \\
\hline 24 & $\begin{array}{lll}6 & 23 & 20\end{array}$ & to $26.4 \mathrm{I}$ & -155.7 & I & $2 \mathrm{~J} \quad 54 \quad 41.55$ & $9.059 n$ & $+623 \times 9.8$ & $0.8 \times 7$ & 2 \\
\hline 26 & $\begin{array}{lll}7 & 34 & 59\end{array}$ & -131.92 & -319.9 & 8 & $\begin{array}{lll}21 & 58 & 33.39\end{array}$ & $7 \cdot 320_{n}$ & +52955.2 & 0.915 & 3 \\
\hline
\end{tabular}

Mittlere.Oerter der Vergleichsterne für ${ }_{1} 884.0$.

\begin{tabular}{|c|c|c|c|}
\hline 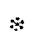 & $\alpha \mathbf{1} 884.0$ & $\delta$ I 884.0 & Autorität \\
\hline $\mathbf{I}$ & $21^{\mathrm{h}} 52^{\mathrm{m}} \times 3^{\mathrm{s}} \cdot 65$ & $+6^{\circ} 43^{\prime} 35^{\prime \prime} 8+28.4$ & BB. VI $+6^{\circ} 4934$ \\
\hline 2 & $21 \quad 54 \quad 11.95$ & $+62443.2+28.3$ & BB.VI $+6^{\circ} 4939$ \\
\hline 3 & +3.20 & $+53247.1+28.0$ & Schjell. 9015 \\
\hline
\end{tabular}

B e m e r k unge $\mathbf{n}$.

Oct. 24. Nur eine Vergleichung zwischen Wolken.

26. Unter Wolken. Comet schwach, auch Mond schon etwas störend. Der Vergleichstern findet sich auch in B. Z. 6 ; diese Position weicht aber von Schjell. um $+\mathbf{1}^{\mathrm{s}} . \mathrm{I} 5$ und $+5.5 \mathrm{ab}$.

Alle Beobachtungen an hellen Fäden.

Kiel $188_{4}$ Oct. 27 .

Auf der Sternwarte in Plonsk. (Fortsetzung.)

\begin{tabular}{|c|c|c|c|c|c|c|c|c|c|}
\hline 1884 & T.M.Plonsk & $\Delta a$ & $1 \delta$ & Pass. & $\alpha$ app. & $\log p \cdot A$ & $\delta$ app. & $\log p \cdot 1$ & $\%$ \\
\hline Sept. 24 & $8^{\mathrm{h}} 56^{\mathrm{m}} 20^{\mathrm{s}} \cdot 2$ & $-2^{\mathrm{m}} 6.72$ & $-6^{\prime} 48.9$ & 8 & $21^{\mathrm{h}} 17^{\mathrm{m}} 18.92$ & $7.910_{11}$ & $+20^{\circ} 39^{\prime} 44^{\prime \prime} \circ$ & 0.668 & 2 \\
\hline 29 & $\begin{array}{lll}8 & 2 \mathrm{I} & 4 \mathrm{I} .4\end{array}$ & $+2 \quad 6.54$ & -121.0 & 6 & $21 \quad 20 \quad 48.44$ & $8.587 \mathrm{u}$ & $\begin{array}{lll}\text { + } 18 & 14 & 2.5\end{array}$ & 0.699 & 3 \\
\hline Oct. 7 & $7 \quad 40 \quad 30.0$ & +r $5^{2.55}$ & +653.6 & 6 & $\begin{array}{lll}21 & 28 & 47.07\end{array}$ & $8.822_{n}$ & +142656.6 & 0.739 & 4 \\
\hline IO & 7 I 749.5 & - I 36.95 & +5 I 4.5 & 6 & 2 I $32 \quad 28.70$ & $8.95^{\circ} \mathrm{n}$ & +125853.5 & 0.754 & 5 \\
\hline 23 & $\begin{array}{lll}6 & 59 & 48.6\end{array}$ & +228.22 & 44.8 & 7 & $2152 \quad 52.15$ & $8.83^{\circ}$ & +64954.1 & 0.803 & 6 \\
\hline
\end{tabular}

Etoiles de comparaison.

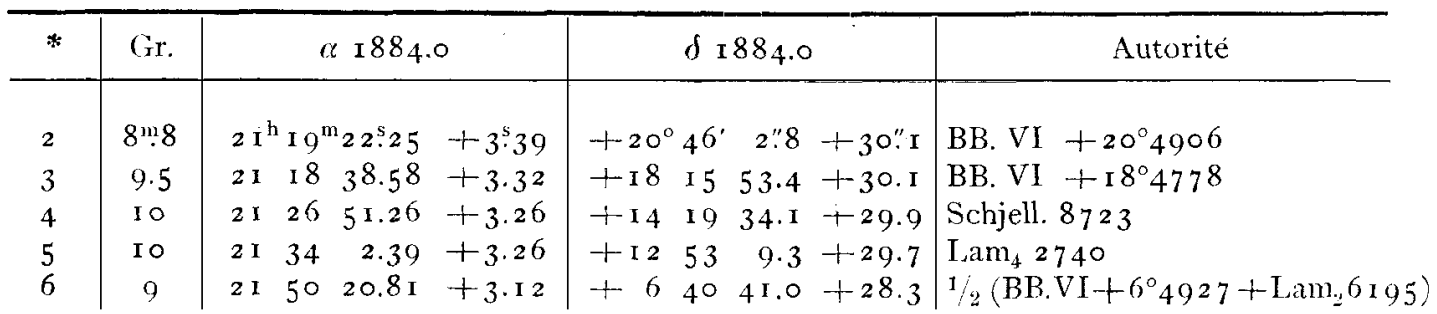

(Instr. Equatorial de Cooke, r $40 \mathrm{~mm}$., micrometre circulaire).

Plonsk I 884 Oct. 24.

Fedrzejewicz.

\section{In lialt:}

7u Nr. 2626-27. A. Weiler. Die Störungen der Erdbahn durch dẹn Jupiter. 145. - G. Celoria. Comete del 1457. 17I. - Mittheilung betrefferid eine Ephemeride des Cometen I884 II (Bamard). I73. - Beobachtungen des Cometen i884 Wolf in Kiel und Plonsk. I75. 